Primljen / Received: 3.11.2015. Ispravljen / Corrected: 12.4.2016.

Prihvaćen / Accepted: 29.6.2016. Dostupno online / Available online: 10.5.2017.

\section{Identification of flutter derivatives by forced vibration tests}

Authors:

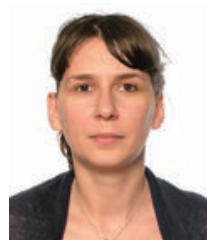

Assist.Prof. Anina Šarkić Glumac, PhD. CE University of Belgrade

Faculty of Civil Engineering

sarkicanina@gmail.com

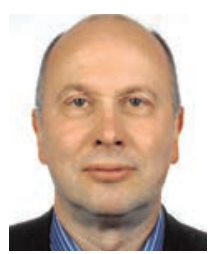

Prof. Rüdiger Höffer, PhD. CE

Ruhr-University Bochum, Bochum

Building Aerodynamics Laboratory

ruediger.hoeffer@ruhr-uni-bochum.de

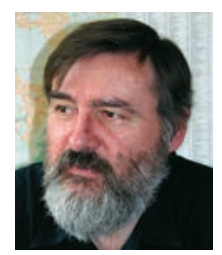

Prof. Stanko Brčić, PhD. CE University of Belgrade Faculty of Civil Engineering stanko.brcic@gmail.com

\section{Anina Šarkić Glumac, Rüdiger Höffer, Stanko Brčić}

Original scientific paper

\section{Identification of flutter derivatives by forced vibration tests}

Results of an experimental study related to flutter phenomenon are presented in the paper. Two cross-sections are considered: a rectangular cross-section and a typical symmetric bridge cross-section. Stationary coefficients and instationary flutter derivatives are determined by means of forced vibration tests. The identification technique is presented in detail. Pressure measurements at the centre of the bridge cross-section are also performed. Main wind flow patterns are analysed based on pressure distribution data.

\section{Key words:}

aeroelasticity, flutter, flutter derivatives, forced vibration test, rectangular cross-section, bridge cross-section

Izvorni znanstveni rad

\section{Anina Šarkič Glumac, Rüdiger Höffer, Stanko Brčić}

\section{Identifikacija parametara treperenja testovima prisilnih vibracija}

U radu su prikazani rezultati eksperimentalnog istraživanja vezanoga za pojavu treperenja. Promatrana su dva poprečna presjeka: pravokutan i tipičan simetričan poprečni presjek mosta. Posebno su određeni ustaljeni koeficijenti kao i neustaljeni parametri treperenja primjenom testova prisilnih vibracija. U radu je detaljno prikazana postupak identifikacije. Uz to, na središnjem poprečnom presjeku mosta provedena su mjerenja tlakova. Na osnovi raspodjele tlakova analizirane su glavne sheme obstrujavanja vjetra.

Ključne riječi:

aeroelastičnost, treperenje, parametri treperenja, test prisilnih vibracija, pravokutni poprečni presjek, poprečni presjek mosta

Wissenschaftlicher Originalbeitrag

Anina Šarkić Glumac, Rüdiger Höffer, Stanko Brčić

\section{Identifizierung von Flatterparametern durch Schwingungsversuche}

In dieser Arbeit werden Versuchsresultate aus Untersuchungen zum Auftreten des Flatterphänomens dargestellt. Es werden zwei Querschnitte betrachtet: ein rechteckiger und ein typischer symmetrischer Brückenquerschnitt. Insbesondere wurden stabile Koeffizienten sowie labile Flatterparameter durch Schwingungsversuche ermittelt. Das Identifizierungsverfahren wird in der Arbeit detailliert dargestellt. Ebenso wurden am mittleren Brückenquerschnitt Druckmessungen durchgeführt. Basierend auf der Druckverteilung wurden die Hauptausrichtungen der Windströmungen analysiert.

Schlüsselwörter:

Aeroelastizität, Flattern, Flatterparameter, Schwingungsversuche, rechteckiger Querschnitt Brückenquerschnitt 


\section{Introduction}

Earliest wind-induced accidents involving suspension bridges were reported in the early 19th century. Nevertheless, in these times, such collapses were simply classified as "wind-related failures" [1]. In order to enable proper realization of these challenging structures, certain wind characteristics had to be recognized as well. It was not until the infamous collapse of the suspension bridge over the Tacoma Narrows, USA, in 1940 [2, 3], that dynamic effects of wind load became recognized and gained importance. It is interesting to note that this bridge was statically designed to withstand very high wind speeds but collapsed under a relatively low wind speed of $19 \mathrm{~m} / \mathrm{s}$. Two crucial issues were not considered until that time:

- dynamic nature of wind action and its interaction with the dynamics of flexible structures

- existence of some forms of aeroelastic behaviour that can radically modify excitation patterns [1].

These interactions of an oscillating structure and surrounding fluid can give rise to a number of different aeroelastic phenomena, including the flutter phenomenon. The investigations following this incident marked the beginnings of a major research discipline where aerodynamic techniques and theories, developed for solving "flutter" instability of aircraft wings, started to be applied to civil engineering structures as well [4]. In this respect, mathematical formulation of bridge flutter, introduced in 1971 by Scanlan and Tomko [5], still remains one of the most widely used formulations for bridge flutter analysis. Frequency dependent aeroelastic coefficients, called flutter derivatives, were introduced to enable aeroelastic load determination. In addition, a standard method for identification of those instationary coefficients was defined for wind tunnel experiments. This has stimulated development of experimental techniques for the measurement of these coefficients.

The goal of this paper is to present an experimental study relating to determination of the Scanlan's system of linear equations, which are main input parameters for analysing flutter of two different cross-sections: a rectangular cross-section, and a common symmetric bridge deck cross-section. An overview of experimental approaches is also given, as well as the detailed flutter derivative identification algorithm. In addition to force balance tests, pressure measurements, including pressure distribution along the tested cross-sections, are also reported.

\subsection{Flutter}

Flutter is a dynamic instability in which the energy drawn from the flow increases the energy of bridge deck oscillations. It can lead to violent oscillations and therefore to structural collapse. Traditionally, flutter is an aeroelastic phenomenon embodying multiple degree of freedom instability but, in most cases, two eigenmodes, vertical bending and torsional bending, couple in a flow-driven unstable oscillation. Typical cross-sections prone to this instability are airfoils and streamlined bridge decks. The motion is characterized by the fluid forces feeding energy into the system during one cycle of its oscillation. This exchange of energy is driven by the phase shift between the vertical and torsional oscillations [6] and it counteracts the energy absorbed by structural damping. Namely, as explained in [7], at low wind speeds the structure usually releases energy to the flow so that the total damping (structural and aerodynamic) increases. After reaching certain wind speed, the energy exchange reverses in the sense that the vibrating structure starts extracting energy from the fluid. The critical condition is reached when the aerodynamic force becomes equal to the dissipated force. In this case, structural oscillations are characterized by zero total damping. By further increase in wind speed, the heaving and torsional motions tend to diverge (negative total damping). Other than affecting the total damping, this energy exchange affects the frequency as well. In particular, the torsional frequency tends to decrease with an increase in wind speed, while the bending frequency remains almost constant. Just before the flutter, the bending frequency sharply increases, jumping to the same value assumed by torsional frequency. It can be said that the torsional frequency suddenly appears as dominant frequency in the vertical bending spectrum [7]. Similar observations related to the Izmit suspension bridge are presented in [8]. At this point, the structure vibrates with the same frequency in bending and torsion, but it is still stable. However, a small increase in wind speed results in the onset of flutter [9].

Flow separation is not necessary for the occurrence of flutter. Furthermore, the fact that this phenomenon occurs at flow velocity above the critical vortex shedding velocity clearly distinguishes the flutter from resonance problem [10]. The critical state can be influenced by acting on the geometry of the section as well as on the damping, and by changing the ratio between natural frequencies. The flutter instability is extremely sensitive to the frequency separation. Namely, the critical flutter wind velocity increases with an increase in the frequency ratio (torsional frequency versus bending) [11]. A special case when torsional frequency is equal to or lower than the bending frequency is worth mentioning. In this particular case, the two degree of freedom flutter is not possible. This was pointed out by Richardson leading to the "flutter free" patent application for twin suspension bridges [12]. Studies related to this innovative solution are presented in [13,14] but, when considering bridge design with torsional frequency lower than the corresponding bending frequency, it is necessary to check whether the torsional divergence [7] and vortex shedding excitation [8] might jeopardize the structure.

A method in which aerodynamic parameters - flutter derivatives - are applied to define a linear aeroelastic subsystem is presented in [5]. Flutter derivatives are usually identified in experiments and are used to estimate motion-induced forces (also called aeroelastic or self-excited forces). In this respect, the aeroelastic lift and moment forces per unit span-length can be expressed in the extended force model from [15] using differential equations, Eq. (1) and Eq. (2). 
$L_{\mathrm{ae}}=\frac{1}{2} \rho U^{2} B\left[K H_{1}^{*} \frac{\dot{z}}{U}+K H_{2}^{*} \frac{B \dot{\alpha}}{U}+K^{2} H_{3}^{*} \alpha+K^{2} H_{4}^{*} \frac{z}{B}\right]$

$M_{\mathrm{ae}}=\frac{1}{2} \rho U^{2} B^{2}\left[K A_{1}^{*} \frac{\dot{z}}{U}+K A_{2}^{*} \frac{B \dot{\alpha}}{U}+K^{2} A_{3}^{*} \alpha+K^{2} A_{4}^{*} \frac{z}{B}\right]$

In these equations, $\rho$ is the air density, $U$ is the undisturbed or mean oncoming wind velocity, $B$ is the section width, $K=B \omega / U$ is the reduced frequency, and $H_{i}^{*}, A_{i}^{*}(i=1 . .4)$ are the flutter derivatives. A set of flutter derivatives is usually evaluated for a specific cross-sectional shape of a bridge deck. Each derivative is a dimensionless function of reduced frequency or more commonly, of reduced velocity, $U_{\text {red }}=U / B f$. Besides this traditional approach in the frequency domain, the time domain approach is also applied. Relatively bluffer cross-sections undergoing strongly separated flows are prone to the single degree of freedom torsional instability, which is called torsional flutter. The tendency of this instability can be observed in the pattern of the $A_{2}{ }^{*}$ flutter derivative, having a physical meaning of aerodynamic damping in pitch.

\subsubsection{Bridge flutter model}

The first description of motion-induced forces at a flat plate was published in [16]. The solution was derived in a closed analytical form obtained using potential theory. Yet, theoretical functions describing these instationary forces can not be derived for common bridge deck sections. Still, a formulation analogous to the one presented in [16] is adopted in terms of frequencydependent parameters (cf. Eq. (1) and Eq. (2))

The aeroelastic force model presented in Eq. (1) and Eq. (2) is based on two assumptions. The first assumption is that the motion-induced lift force and moment on a bluff body can be described as linear function of structural displacements $z$ and rotation $\alpha$ and their first and second order derivatives $\dot{z}, \dot{\alpha}, \ddot{z}, \ddot{\alpha}$, as presented in [17]:

$F=F(z, \alpha, \dot{z}, \dot{\alpha}, \ddot{z}, \ddot{\alpha})=P_{\mathrm{z}} z+P_{\alpha} \alpha+P_{\dot{z}} \dot{z}+P_{\dot{\alpha}} \dot{\alpha}+P_{\ddot{z}} \ddot{z}+P_{\ddot{\alpha}} \ddot{\alpha}$

where $F$ stands either for the self-excited (aeroelastic) lift force $L_{\mathrm{ae}}$ or the self-excited moment $M_{\mathrm{ae}}$ and $P_{\mathrm{i}}(i=z, \alpha)$ are self-excited force parameters. This assumption is treated as valid due to limited oscillation amplitudes at the onset of flutter [16]. The second assumption is related to the existence of harmonic motions with a single frequency at the onset of flutter. Thus, the displacement and its first- and second-order derivatives can be expressed as:

$x=\hat{x} e^{i \omega t}, \dot{x}=\hat{x} i \omega e^{i \omega t}, \ddot{x}=-\hat{x} \omega^{2} e^{i \omega t}$

where $\hat{x}$ is the amplitude of displacement $(x=z, \alpha)$ and $\omega$ is the circular frequency of motion. It can be observed that parts related to the displacements and accelerations can be combined based on Eq. (3) and Eq. (4). This is consistent with the representation given in Eq. (1) and Eq. (2) and it allows certain interpretation of flutter derivatives as parts of motion-induced forces. Namely, these forces feed back into structural dynamics as aeroelastic damping, through derivatives $H_{1}{ }^{*}, H_{2}{ }^{*}, A_{1}{ }^{*}, A_{2}{ }^{*}$ and coupled aeroelastic stiffness and masses $H_{3}{ }^{*}, H_{4}{ }^{*}, A_{3}{ }^{*}, A_{4}{ }^{*}$. The validity of the linear model for bridge deck self-exited forces is an important issue. One of important effects is the dependence of flutter derivatives on the amplitude of motion [18]. In addition to the above-presented convention for flutter derivatives, some other conventions are also used, as shown in [19, 20].

\subsubsection{Identification of flutter derivatives}

Flutter derivatives are usually determined experimentally in wind tunnel tests for individual bridge deck geometries. Two major experimental strategies are used for this purpose: the forced vibration method and the free vibration method. In free vibration experiments a section model is elastically supported by springs and possibly by dampers, which are mounted in a wind tunnel. Some examples of identification techniques for extracting the flutter derivatives can be found in [21-23]. In the case of forced vibration tests, a motor and a kinematic mechanism must exist in order to drive the model harmonically in its degrees of freedom. Motion-induced forces can be obtained directly either through force or pressure measurements. Examples of identifying flutter derivatives of bluff bodies (rectangular prisms) using pressure measurements can be found in [24, 25].

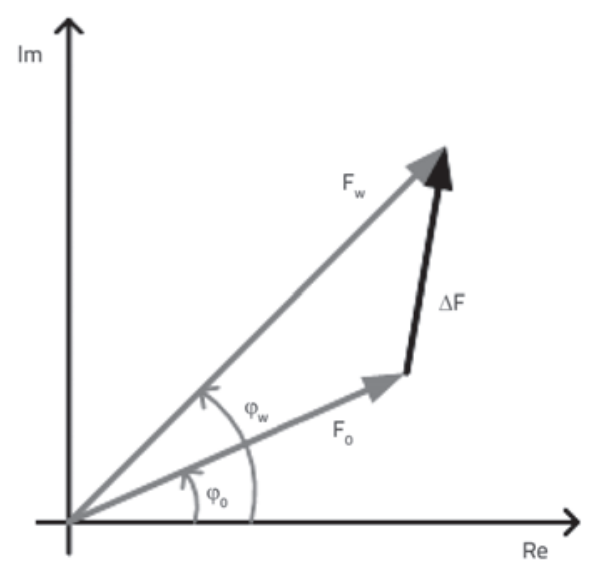

Figure 1. Identification of aeroelastic forces in complex plane [26]

The forced vibration method with prescribed harmonic motions is applied in this study. The forces are measured using force balances. For such an identification method, it is of utmost importance to separate small signals of aeroelastic forces acting on the bridge deck model from larger signals due to inertial forces of the model itself. Two sets of measurements are therefore conducted. First, a reference measurement is made with forced vibrations in still air to identify inertia forces. In the second step, measurements are repeated under the wind tunnel flow action, thus measuring inertia and aeroelastic 
forces together. Identical oscillation frequency and amplitude must be used in both cases. Since the applied forced motion is harmonic, these measured forces are also assumed to be harmonic. Therefore, forces measured in still air $F_{0}$ and under the action of the wind $F_{w}$ can be expressed as:

$F_{0}=\hat{F}_{0} e^{i\left(\omega t+\varphi_{0}\right)}, F_{\mathrm{w}}=\hat{F}_{\mathrm{w}} e^{i\left(\omega t+\varphi_{\mathrm{w}}\right)}$

where $\hat{F}_{0}$ and $\hat{F}_{w}$ are force amplitudes and $\varphi_{0}$ and $\varphi_{w}$ are phase shifts for the applied motion given in Eq. (4), related to measurements in still air and under wind action, respectively (cf. Figure 1). The aeroelastic forces are obtained by calculating the difference between these two sets of measurements, see [27] and Figure 1:

$\Delta F=F_{\mathrm{w}}-F_{0}$

It may be seen, as presented in Appendix, that flutter derivatives related to vertical motion can be obtained from:

$\frac{1}{2} \rho K^{2} U^{2} \hat{z}\left[H_{4}^{*}(K)+i H_{1}^{*}(K)\right]=\Delta L_{\mathrm{ae}}^{z}(K)$

$\frac{1}{2} \rho K^{2} U^{2} B \hat{z}\left[A_{4}^{*}(K)+i A_{1}^{*}(K)\right]=\Delta M_{\mathrm{ae}}^{\mathrm{z}}(K)$

and related to torsional motion from

$\frac{1}{2} \rho K^{2} U^{2} B \hat{\alpha}\left[H_{3}^{*}(K)+i H_{2}^{*}(K)\right]=\Delta L_{\mathrm{ae}}^{\alpha}(K)$

$\frac{1}{2} \rho K^{2} U^{2} B^{2} \hat{\alpha}\left[A_{3}^{*}(K)+i A_{2}^{*}(K)\right]=\Delta M_{\mathrm{ae}}^{\alpha}(K)$

where $\Delta L_{\mathrm{ae}}^{\alpha}$ and $\Delta M_{\mathrm{ae}}^{\alpha}(\mathrm{x}=\mathrm{z}, \alpha)$ are the mentioned differences for the aeroelastic lift and for the aeroelastic moment, respectively. For example, it is clear from Eq. (7) that:

$H_{1}^{*}=\frac{2 \operatorname{lm}\left(\Delta L_{\mathrm{ae}}^{\mathrm{z}}\right)}{\rho K^{2} U^{2} \hat{z}}$

$H_{4}^{*}=\frac{2 \operatorname{Re}\left(\Delta L_{\mathrm{ae}}^{\alpha}\right)}{\rho K^{2} U^{2} \hat{z}}$

Other expressions can be derived in a similar manner. Further details regarding the identification algorithm can be found in [26]. Thus, the procedure can be summarized as:

- perform forced oscillation tests in still air and under wind action in either vertical (heave) or torsional (pitch) motion for each reduced velocity $U_{\text {red }}$ that is of interest,

- calculate the best-fit harmonic of the same forcing frequency to obtain force amplitude coefficients and phase shifts related to the applied motion, Eq. (5)

- calculate the derivatives from Eqs. (7-10).
Flutter derivatives are defined in this work according to the convention in which the lift force and the heaving displacement are positive upward, while the aerodynamic moment and the pitching rotation are positive for a nose-up rotation.

\section{WIST boundary layer wind tunnel}

All fixed and forced vibration experiments have been performed in the WIST (Windingenieurwesen und Strömungsmechanik) boundary layer wind tunnel at Ruhr University Bochum. The wind tunnel with the test section is shown in Figure 2. The open circuit wind tunnel is $9.4 \mathrm{~m}$ in total length, $1.8 \mathrm{~m}$ in width, and $1.6 \mathrm{~m}$ in height. The upper ceiling is flexible, and can be raised up to $1.9 \mathrm{~m}$. The diffuser and the centrifugal fan are located at the end of the wind tunnel. The maximum wind speed is approximately $30 \mathrm{~m} / \mathrm{s}$ at 1500 revolutions per minute.

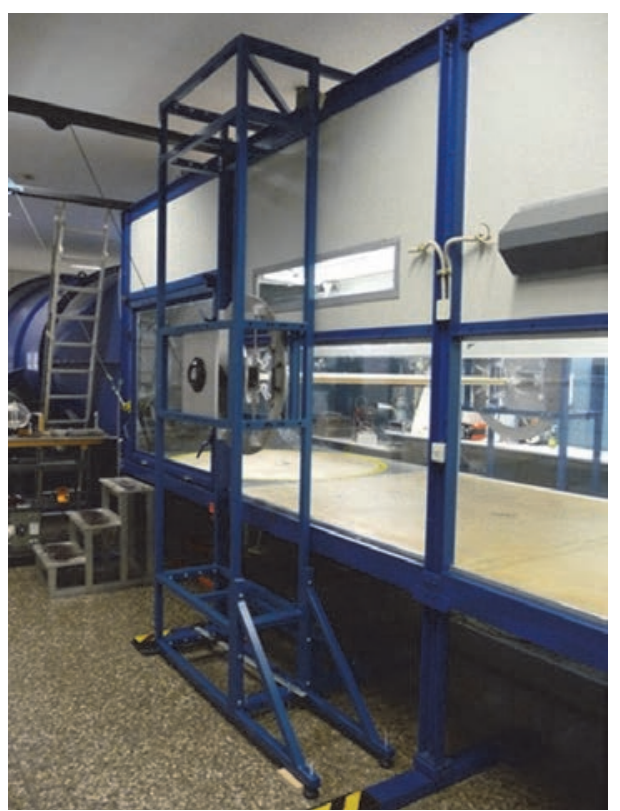

Figure 2. View of boundary layer wind tunnel at Ruhr University Bochum

A Prandtl tube is placed so that it is out of the influence of the wind tunnel walls. It is typically at the height of $1.3 \mathrm{~m}$ from the wind tunnel bottom, but the position may vary depending on the test. The Prandtl tube is used for measuring dynamic pressure of the incoming flow. The test temperature is obtained using temperature sensors. The mean wind speed can be acquired using Bernoulli equation.

All measurements are performed in wind field, where the inflow turbulence is induced by the honeycomb grid only. The honeycomb grid is located at the inlet of the tunnel, as shown in Figure 3. No additional turbulence generators are applied. The turbulence intensity is estimated at approximately 3-4\% and the integral turbulence length scale is around $0.03 \mathrm{~m}$. 


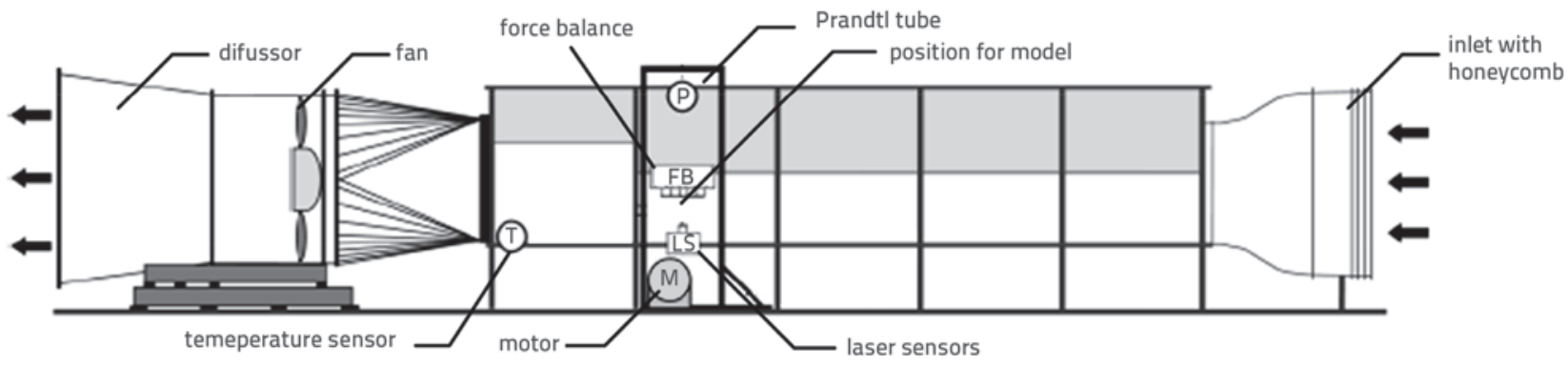

Figure 3. Detailed view of boundary layer wind tunnel at Ruhr University Bochum

\subsection{Forced vibration experimental setup}

Forced vibration equipment can be divided into three general parts: equipment related to excitation mechanism, force measurement equipment and displacement measurement equipment.

A steel frame is mounted outside the wind tunnel for handling of all mechanical parts and measurement devices used in forced vibration testing. In this way, the measurements are not disturbed by excitation mechanism. The frame position is shown in schematic presentation of wind tunnel given in Figure 3. A three phase electric motor with a rated power of $5.5 \mathrm{~kW}$ is placed under the wind tunnel. The motor is driving a shaft that extends from one side of the wind tunnel to the other. At these ends, there are two steel discs that move the test model, cf. Figure 4.a. Certain modifications of disc-related mechanical parts are needed to achieve different motions of the model. More details can be found in [26].

The use of this equipment is subject to some limitations. The maximum possible amplitude in vertical and horizontal directions is $7.5 \mathrm{~cm}$ and the rotation angle is $\pm 15^{\circ}$. The maximum engine speed is $435 \mathrm{rpm}$ and the allowable oscillation frequency varies from $0.3 \mathrm{~Hz}$ to $7.5 \mathrm{~Hz}$.

Overall forces acting on the model section in wind tunnel are measured by two force balances placed at the ends of the rig. A schematic view of the force balance is given in Figure 4.a. Each force balance is equipped with strain gauges, placed on the forcebalance arms, as shown in Figure 4.b. In this way, two vertical forces and one horizontal force are measured. The definition of the forces is presented in Figure 4.c. Three forces $L, D$ and $M$ are evaluated based on the forces measured on both sides of the wind tunnel. An appropriate calibration is necessary for this purpose. Namely, these forces are obtained using the calibration matrix. The calibration matrix is established by applying a certain number of static tests with different known forces. Different masses and points of actions have to be applied in this procedure. Based on all these test combinations, the calibration matrix is obtained using the least-square method. The effect of inertia forces is an important limiting factor that must be taken into account. In order to reduce the influence of inertia the force balance has to be positioned near the model.

Model displacements are measured by two electro-optical laser sensors. This is done by tracking the position of the base point of the force balance on each side of the wind tunnel. In case of pitch measurements, these displacements are transformed into the rotation angle. Figure 4 a shows the position of the base point of the electro-optical sensor. A schematic view of the entire force vibration equipment is given in Figure 4. More details related to the force vibration equipment are presented in [28, 29].

\subsection{Pressure measurements}

Besides measuring motion-induced forces, pressure measurements were also utilized in this experimental campaign. The equipment needed to conduct these pressure measurements consists of forty pressure transducers (sensors), a tubing system, amplifiers and analogue-digital (A/D) converters.

Two types of pressure transducers were used for this study:

- Honeywell 170 PC sensors

- AMSYS 5812-0001-D-B sensors.
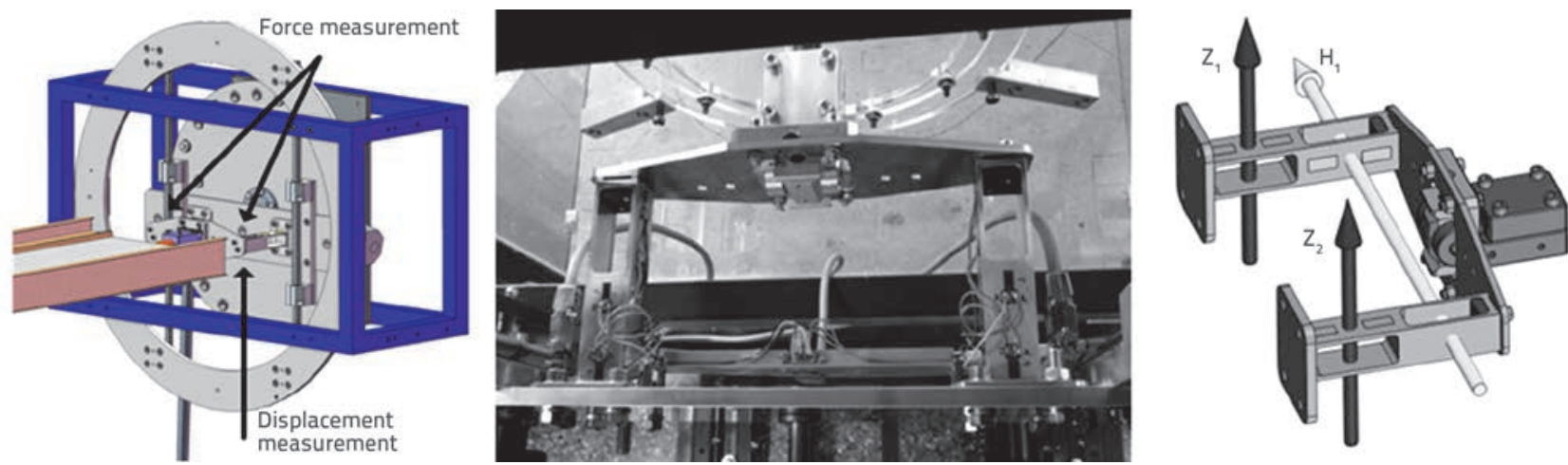

Figure 4. a) Force balance with positions of strain gauges and base point for displacement measurements; b) force balance in wind tunnel; c) definition of forces [26] 
A schematic view of the Honeywell-type pressure sensor, with two chambers separated by one piezoresistant membrane, can be seen on the left side in Figure 5. The membrane loaded with a pressure difference from the chambers results in a deformation, which is associated with the change of resistance in piezoresistors. Both sensor types (Honeywell and AMSYS) operate according to the same principle, by measuring differential voltage, and hence differential pressures. In this particular case of measurements, the pressure difference is realized as a difference of pressures at model surfaces and static pressure in Prandtl tube.

The amplifiers for the Honeywell pressure sensors are external and independent from each other. On the other hand, the amplifiers of the AMSYS pressure sensors are incorporated within the pressure cells. All analogue signals are then converted to digital ones, using analogue-digital (A/D) converters. A general pressure-measurement principle is shown in Figure 6 . The pressures are scanned with the sampling rate of $1000 \mathrm{~Hz}$ in a sample-and-hold mode, which produces simultaneous sampling of pressures. The software used for recording is SBench 5.0.

The pressure data calibration process includes two phases: static and dynamic. The main purpose of static calibration is to determine the pressure-voltage relations for each pressure sensor. This calibration is performed at the pressure sensor setup corresponding to actual measurement situations. For that purpose, a Betz manometer is used, allowing application of known pressures to the sensors. In this way, the link between

the measured voltage and known pressure is established. The following relationships have been acquired for the described measurements: 5 mbar corresponds to $5 \mathrm{~V}$ for Honeywell sensors, and 5 mbar corresponds to $1 \mathrm{~V}$ for AMSYS sensors.

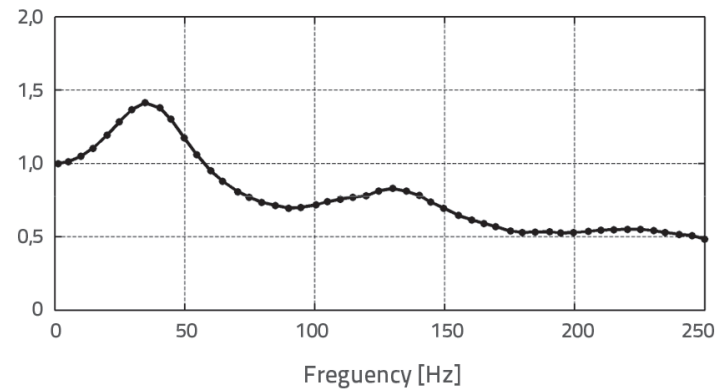

Figure 7. Transfer function of tubing system for pressure measurements

The dynamic calibration is related to the added acceleration response of the tubing system. It is important to note that the tubing system is a necessity. This is due to the fact that space restrictions in the model do not generally permit placement of pressure sensors directly onto the model surface. In this particular case, the tubes connecting the pressure sensors to the bores are approximately $1.5 \mathrm{~m}$ in length. As pressures on model surface must be measured, the dynamic response added to the signals by tubing must be eliminated. This is accomplished in two steps. The first step serves to quantify these effects and the second one to remove these effects from the measured signal. These undesirable effects

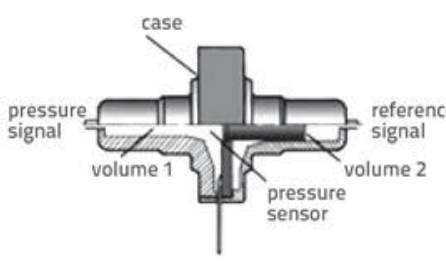

Figure 5. Pressure sensor - Honeywell (left) and pressure cell - AMSYS (right)

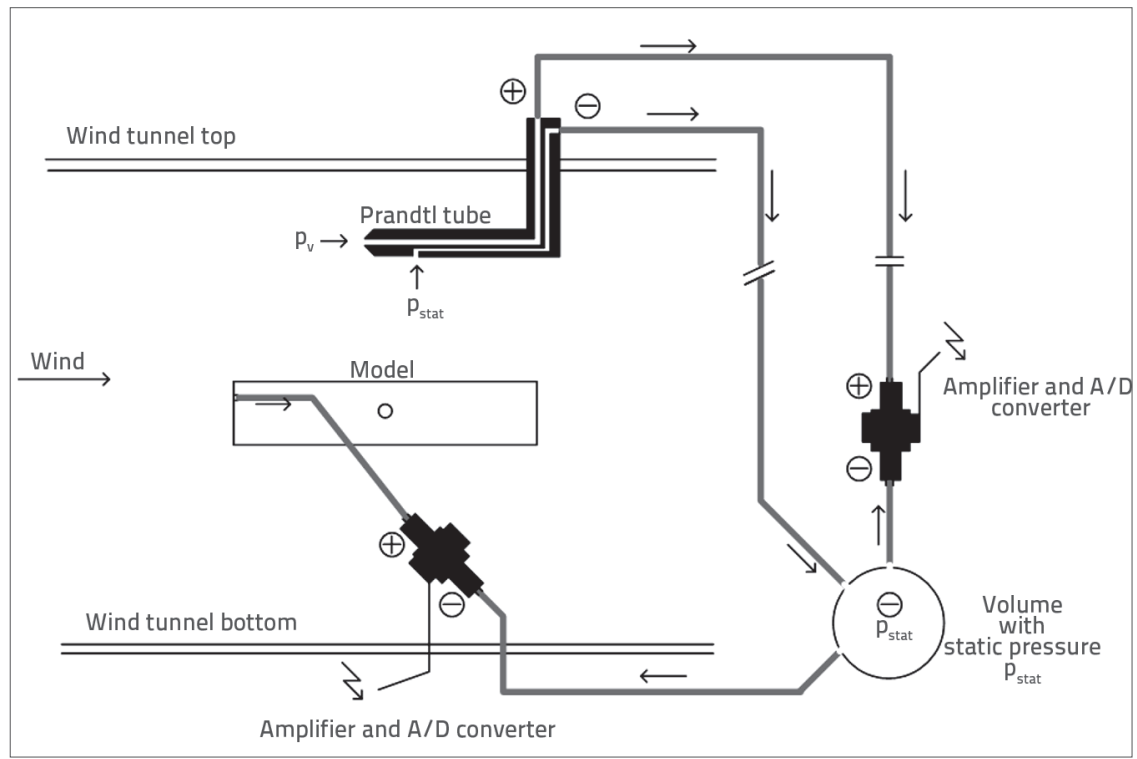

Figure 6. Tubing system for pressure measurements are identified by comparing the response spectrum of the measured signal when the tubes are used with the signal when the tubes are not used, i.e. when the sensor is applied directly on the surface of a model. The latter is considered to be the right measurement. These effects are captured with the transfer function of the pressure tubes, as shown in Figure 7. Using this procedure, the transfer function is evaluated based on the reference measurement of the signal. As it can be observed from transfer function presented in Figure 7, the tube amplifies the amplitudes of the frequencies lower then $65 \mathrm{~Hz}$, and damps the amplitudes of the frequencies that exceed this value. The maximum amplification has been obtained for frequencies of approximately $30 \mathrm{~Hz}$. Unlike this amplitude dependency on frequency, no correction is required in case of phase shift. This is due to the fact that phase shifts result in a linear function of the frequency, providing a constant time shift of $0.005 \mathrm{~s}$ for all frequencies. In the second step, this residual influence on the pressure measurements is corrected by means of a digital filter using the MATLAB routine. Digital filter corrects frequencies of up to 
$200 \mathrm{~Hz}$, and this frequency becomes the cut-off frequency. More details on the transfer function and digital filter used in this study can be found in [29].

\section{Wind tunnel measurements}

Two different models have been tested:

- a rectangular cross-section, with the width to height ratio $(B / H)$ of 4

- a symmetric, single-box section of a bridge girder.

A schematic drawing of both cross-sections is given in Figure 8.
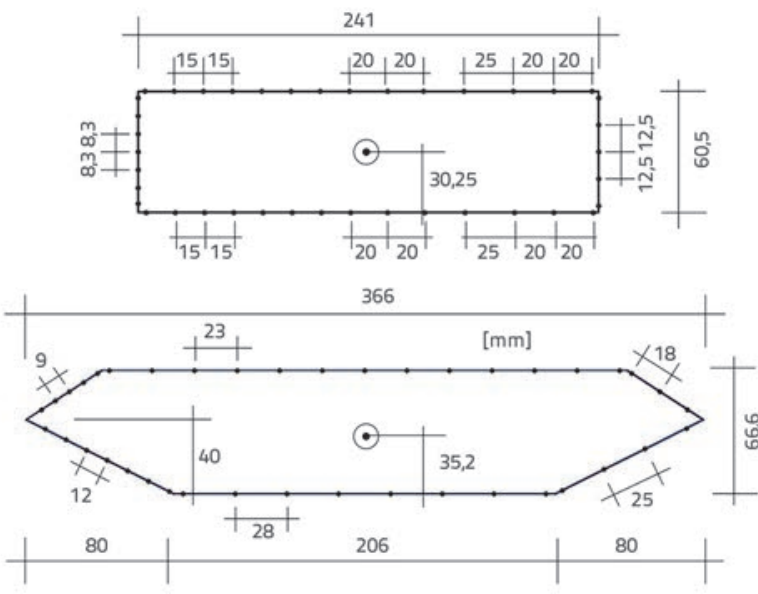

Figure 8. Model of rectangular cross-section and bridge deck with the arrangement of 40 pressure taps

The wooden model of the rectangular cross-section has a width $B$ of $0.24 \mathrm{~m}$, a height $H$ of $0.06 \mathrm{~m}$ and a length $L$ of $1.8 \mathrm{~m}$. The total mass of the model amounts to approximately $4.1 \mathrm{~kg}$. The arrangement of 40 pressure taps positioned around the cross-
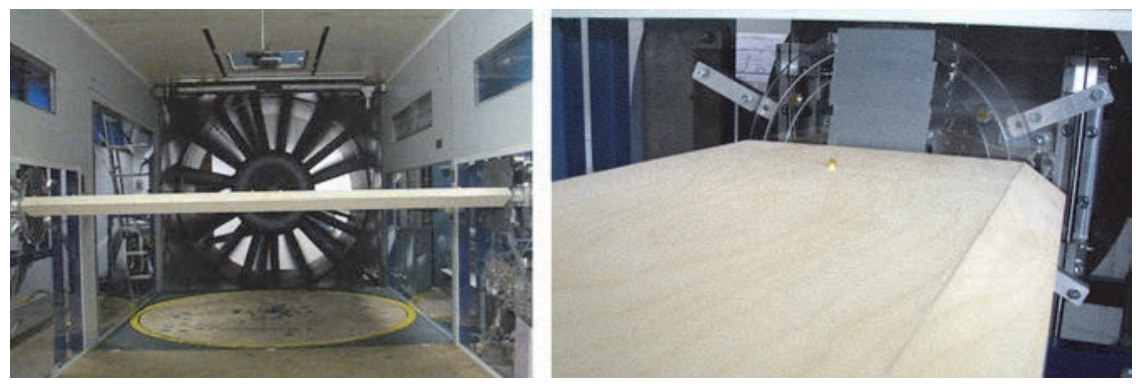

Figure 9. Model of rectangular cross-section placed in experimental rig
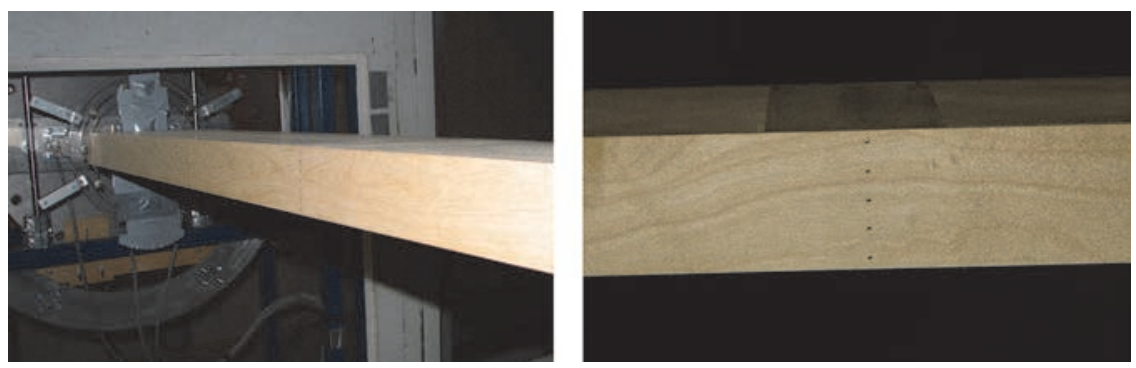

Figure 10. Model of wooden bridge deck section placed in experimental rig section in the middle of the span is presented in Figure 8 above. The blockage ratio at the flow attack of $0^{\circ}$ is approximately $3.4 \%$. The wooden model of the bridge deck has a width $B$ of $0.37 \mathrm{~m}$, a height $H$ of $0.067 \mathrm{~m}$ and a length $L$ of $1.8 \mathrm{~m}$. The total mass of the model is about $4.9 \mathrm{~kg}$. 40 pressure taps are equidistantly placed at each surface around the section, refer to Figure 8 down, in the middle of the span. The blockage ratio at the flow attack of $0^{\circ}$ is around $3.75 \%$. The model is tested in the baredeck configuration, i.e. without non-structural details.

Both tested models fixed in the experimental rig are shown in Figure 9 and Figure 10. Pressure bores at centre span of the rectangular model are also presented on the right side in Figure 10.

\subsection{Fixed-model experiments}

Previously introduced section models are used for the tests with fixed configuration. Before any wind measurements, the models are placed in the experimental rig and model eigenfrequencies are obtained by applying initial impulses on the models and by measuring the force response (measurements in still air). Eigenfrequencies based on the lift force spectrum are estimated and presented in Table 1.

Table 1. Eigenfrequencies related to heave $f_{\mathrm{h}}$ and torsional motion $f_{\mathrm{t}}$ of models

\begin{tabular}{|l|c|c|}
\hline Section Eigenfrequency & $\boldsymbol{f}_{\mathrm{h}}[\mathrm{Hz}]$ & $\boldsymbol{f}_{\mathrm{t}}[\mathrm{Hz}]$ \\
\hline Rectangular & 21,6 & - \\
\hline Bridge & 21,5 & 14,6 \\
\hline
\end{tabular}

It is shown in [30] that a linear relationship exists between the frequency of vortex shedding $\left(f_{\mathrm{s}}\right)$ and the undisturbed flow velocity (U):

$S t=\frac{f_{\mathrm{S}} B}{U}$

St is the dimensionless coefficient known as the Strouhal number. The Strouhal number is dependent on the Reynolds number, especially in the case of rounded crosssections. For cross-sections with sharp edges, vortex shedding is geometrically induced, and the unsteady wake is less sensitive to the Reynolds number.

The Strouhal number is experimentally estimated via tests with different wind speeds. Here the procedure is presented for the case of rectangular cross-section; the same applies for the other test model. Eleven measurements with fixed configuration of the rectangular crosssection at $0^{\circ}$ of flow attack are performed. Wind velocities correspond to the Reynolds numbers in the following range: $3.8 \cdot 10^{4}<$ $R e<31 \cdot 10^{4}$. 

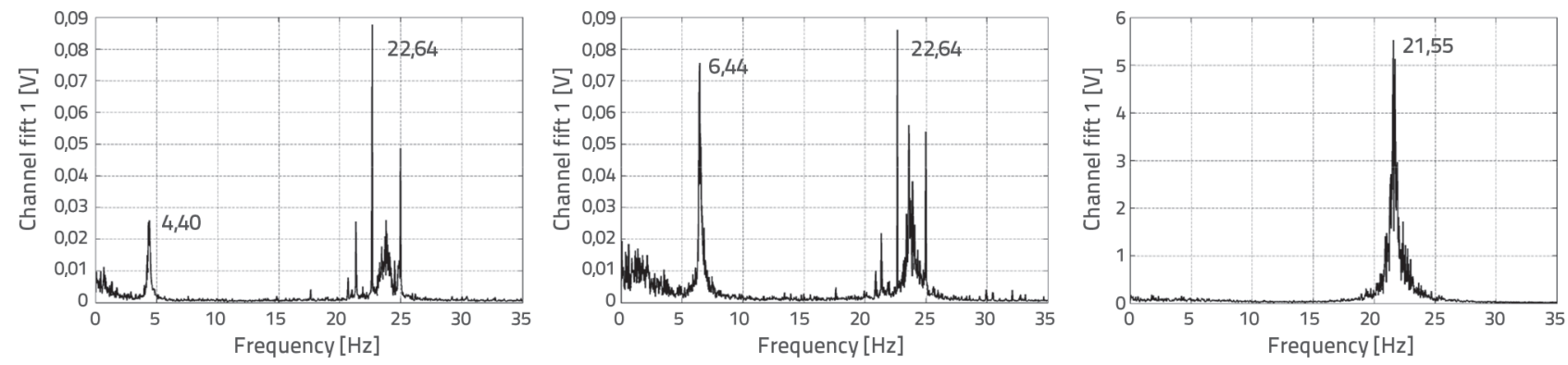

Figure 11. Evaluation of Strouhal number using amplitude spectrum of measured lift force signal of rectangular cross-section

Based on Eq. (13), it may be concluded that, in order to estimate the uniform St number, the change of flow velocity has to result in the change of frequency of the vortex shedding. This reasoning is used for evaluating the St number by means of spectral analysis of the force measurement signals. In fact, the vortex shedding frequency may be estimated in the spectra, tracking the frequencies corresponding to the peaks differing from the eigenfrequency peak. As an example, three amplitude spectra of the lift force signal are shown in Figure 11. It can be observed at the left spectrum and the central spectrum that one peak corresponds to the eigenfrequency of the model, while another peak may be observed on both spectra. This second peak is related to the vortex shedding frequency, and it moves from left spectrum to central spectrum in response to the change in velocity. Only one peak can be observed at the right spectrum, which is due to resonance between the vortex shedding frequency and eigenfrequency. This resonance case is commonly referred to as the lock-in phenomenon. Thus, when the wind speed reaches a value at which the frequency of vortex shedding coincides with the structural eigenfrequency of the bridge, the deck is easily excited into sizable but limited oscillations. This particular aeroelastic phenomenon leads to violation of the Strouhal law (Eq. 13). In that case, the eigenfrequency starts to control the vortex shedding phenomenon even when variation of flow velocity moves the Strouhal number away from the eigenfrequency.

Taking into account the known inlet velocity $U$ and the vortex shedding frequency $f_{s^{\prime}}$ determined based on all test cases and Eq. (13), it has been established that the Strouhal number of the rectangular cross-section based on width lies within the interval $\mu_{S t} \pm \sigma_{S t}=0,518 \pm 0,028$, where $\mu_{S t}$ is the mean value and $\sigma_{S t}$ is the standard deviation of Strouhal numbers. The interval of $\mu_{s t}$ $\pm \sigma_{s t}=0,130 \pm 0,007$ is obtained by normalizing the Strouhal number based on section height. This interval is comparable to the Strouhal number of same cross-section stated in [31], where the value of 0.137 is given (relative difference is $4.82 \%$ ). The same procedure is repeated in the case of bridge deck section. Different wind speeds correspond to the range of $7^{*} 10^{4}<\operatorname{Re}<37^{*} 10^{4}$. Strouhal number of the bridge deck section related to the width of the section lies within the interval $\mu_{S t} \pm$ $\sigma_{s t}=1,301 \pm 0,029$ (or $\mu_{s t} \pm \sigma_{s t}=0,237 \pm 0,005$ related to the bridge section height).

\subsection{Forced-vibration experiments}

The motor and the already discussed kinematic mechanism are used for the forced vibration experiments. Considered crosssections are moved in two degrees of freedom, by applying periodical heaving and torsional motion. The motion in horizontal direction (surge) can also be made via excitation mechanism, but it is not considered in this study. The experimental rig validation is presented in [26].

For the rectangular cross-section, the forced vibration tests are performed using Reynolds numbers in the range of $0.3 \cdot 10^{5}-1.3 \cdot 10^{5}$ and, for the bridge deck section, in the range of $0.6 \cdot 10^{5}-3.5 \cdot 10^{5}$. The applied forced-vibration amplitude is around $1^{\circ}$ for the torsional mode, and the vibration frequency range is $1.0-6.2 \mathrm{~Hz}$.

The purpose of these experiments is to evaluate aeroelastic forces within the range of different reduced velocities. According to the definition of reduced velocity $U_{\text {red }}=U / B f$, this can be accomplished by varying $U$ and $f$, i.e. the inflow velocity and forced frequency, respectively. Detailed planning of the measurements requires setting up appropriate combinations. In this step, limitations of the equipment related to the oscillation frequency and wind speed have to be accounted for. Another important factor that can narrow down the number of possible combinations is related to the previously estimated Strouhal number. In fact, based on the Strouhal number estimation it is possible to evaluate critical velocity related to the mentioned resonant case between the vortex shedding frequency and the eigenfrequency as:

$U_{\text {St, crit }}=\frac{B f_{\text {eigen }}}{S t}$

When this case is reached, i.e. when this velocity is applied, the model is subjected to large oscillations, which makes the measured signals useless [29]. The velocity of $U_{\text {st,crit }}$ must therefore be avoided.

\section{Results and discussion}

If fluctuations due to turbulence are neglected, the created pressures result in mean forces such as: the along-wind drag 
force $D$, the across-wind lift force $L$ and the pitching moment $M$. In non-dimensional form, they are called stationary force coefficients for drag $C_{\mathrm{D}^{\prime}}$ lift $C_{\mathrm{L}}$ and moment $C_{\mathrm{M}}$ :

$$
\begin{aligned}
& C_{\mathrm{D}}(\alpha)=\frac{D}{q_{0} B L_{\mathrm{b}}} \\
& C_{\mathrm{L}}(\alpha)=\frac{L}{q_{0} B L_{\mathrm{b}}} \\
& C_{\mathrm{M}}(\alpha)=\frac{M}{q_{0} B^{2} L_{\mathrm{b}}}
\end{aligned}
$$

where $q_{0}=1 / 2 \rho U^{2}$ is the dynamic pressure, $\rho$ is the air density, $U$ the mean wind velocity, while $B$ and $L_{b}$ are bridge deck width and length values, respectively. These non-dimensional normalized coefficients are generally used to transfer experimentally obtained forces from the wind tunnel model to the design model of the bridge with real dimensions.

Evaluated stationary coefficients, obtained for various angles of flow attack from $-10^{\circ}$ to $10^{\circ}$ using Eqs. (15), based on force balance measurements for rectangular and transverse bridge cross-section, are presented in Figure 12 and Figure 13. In order to check and exclude the dependence on Reynolds number effects, all coefficients are estimated using two different wind velocities. In the case of rectangular cross-section, a small deviation from the expected lift coefficient value, related to the $C_{L}$ coefficient at $0^{\circ}$ angle, can be observed. Also $C_{L}$ curve is not completely symmetric, although this symmetry could be expected since a symmetric cross-section is being considered. This could be due to a small blockage effect due to vertically non-symmetric position of the model in the test section in wind tunnel. In fact, the distance of the rectangular axes to the wind tunnel floor is $72 \mathrm{~cm}$, while the distance to the wind tunnel ceiling is $88 \mathrm{~cm}$.

It is interesting to note that the attack stall condition occurs for higher angles of flow. The stall is a condition in which the lift begins to decrease when the angle of flow attack increases beyond a certain point. In case of the rectangular cross-section, this critical point is not clearly distinguished. Nevertheless the lack of continuous increase of $C_{L}$ values is evident. The stall condition is related to flow separation. Namely, small flow separations might occur at small angles of flow attack. As angle of the attack increases, the separation regions increase in size and hinder the ability to create lift. Such behaviour is not observed in the case of lift coefficients related to the bridge deck section (Figure 13). Here a smooth $C_{L}$ curve is observed, within measured angles of flow attack, with increasing values of lift following an increase in angle.
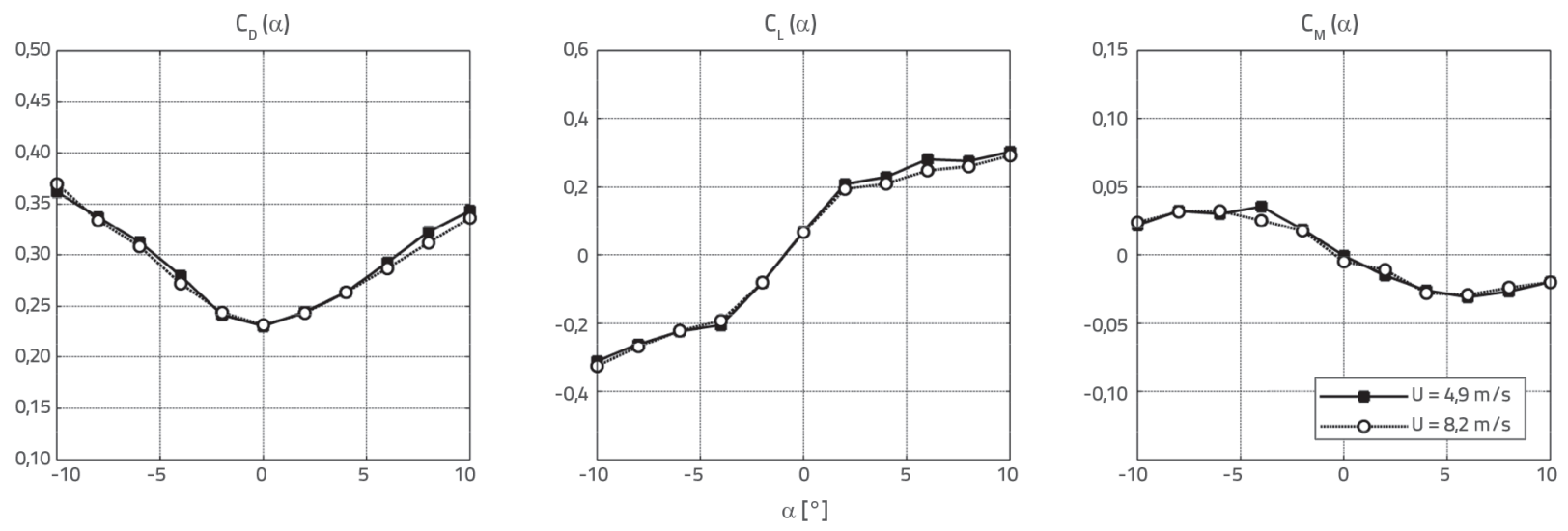

Figure 12. Stationary force coefficients of rectangular cross-section. Angles of attack $\alpha$ are positive nose up
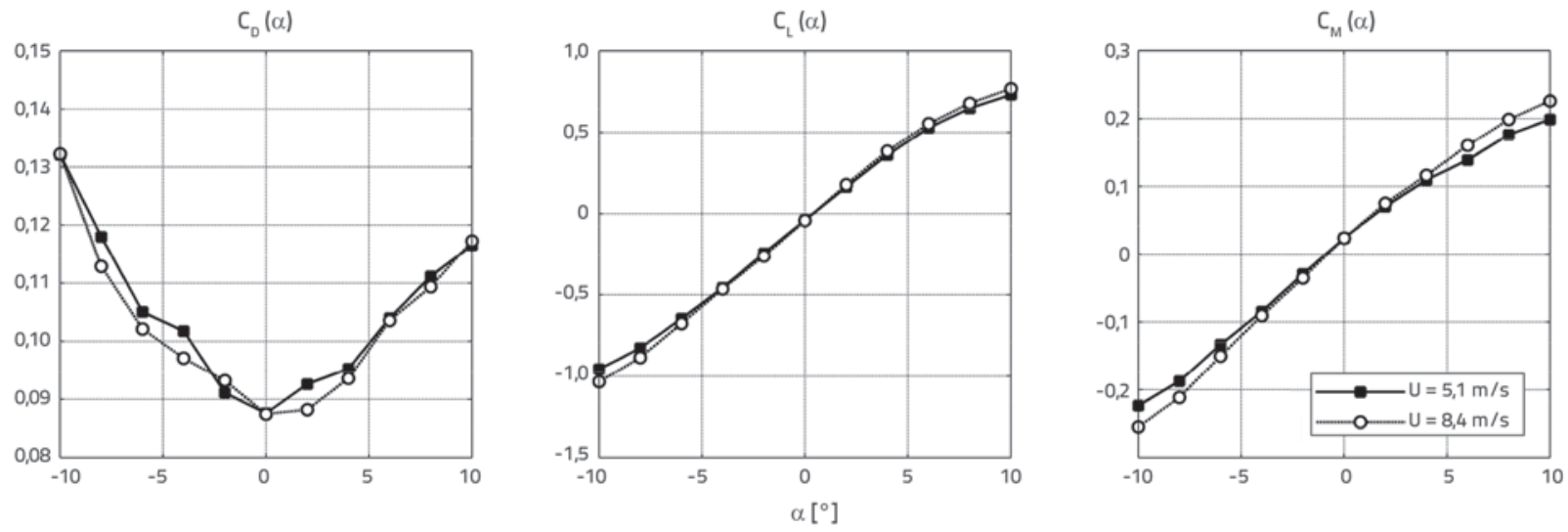

Figure 13. Stationary force coefficients of bridge deck. Angles of attack $\alpha$ are positive nose up 
Other important characteristics of sections in terms of aerodynamic stability are related to the lift and moment coefficient gradients, $d C_{\mathrm{L}} / d \alpha$ and $d C_{\mathrm{M}} / d \alpha$, respectively. The first gradient $\left(d C_{\mathrm{L}} / d \alpha\right)$ can identify if the structure is prone to the so called galloping phenomenon that represents a single degree of freedom instability and may cause the structure to exhibit large amplitude oscillations in the across-wind direction. The main prerequisite is that the lift coefficient must have a strong negative slope (that can even diminish the drag coefficient - Glauert Den Hartog criterion [2]). Since positive slopes are observed in Figures 12 and 13, both considered cases - the rectangular cross-section and the bridge cross-section - are not prone to galloping. Torsional divergence is another instability phenomenon produced by the loss of torsional stiffness due to steady aerodynamic moment. It is related to moment gradient $\left.\left(d C_{\mathrm{M}} / d \alpha\right)\right)$. It can be shown that static divergence can occur only if the moment coefficient is characterized by a positive slope $d C_{\mathrm{M}} / d \alpha(0)>0$ [7]. Figures 12 and 13 show that the bridge cross-section has a positive slope and may lead to this type of instability in contrast to the rectangular cross-section. Critical velocity leading to torsional instability is related to structural characteristics of the real bridge structure, and its analysis is beyond the scope of this paper. Nevertheless, it can be observed that torsional divergence is usually not a cause for high concern in case of real bridges as it tends to appear at sensibly higher wind speed than the flutter $[32,7]$. Nevertheless, this can not be trusted when the frequency ratio between the torsion and bending critical modes is close to or lower than one (e.g. "flutter free" cross-sections mentioned in Section 1.1) [11].

It is common to refer all pressures measured at surfaces to the dynamic pressure $1 / 2 p U^{2}$ of the incoming free-stream wind. Thus dimensionless pressure coefficients $C_{p}$ are defined as:

$C_{p}=\frac{p-p_{0}}{\frac{1}{2} \rho U^{2}}$

a)

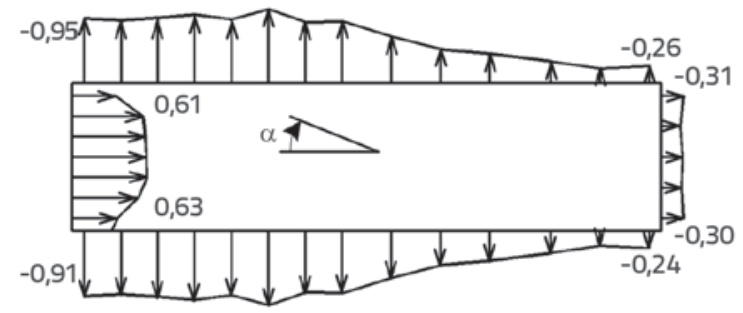

c)

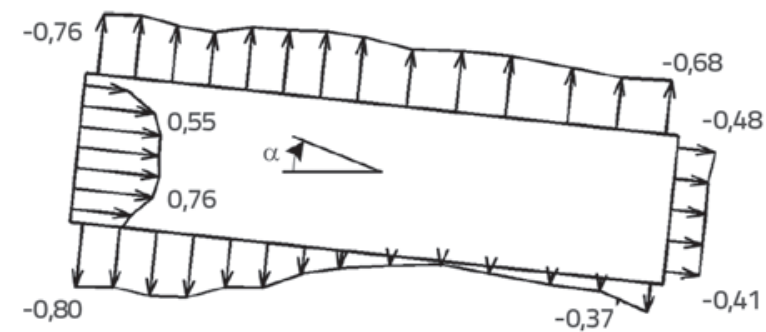

where $U$ is the mean wind velocity and $p-p_{0}$ represents the pressure difference between the local and reference values measured by sensors and explained in Section 2.2. These pressure measurements provide a deeper insight into the flow mechanism. In particular, the measured mean and standard deviation pressure coefficient distributions at 40 pressure taps during tests at fixed cross-section are analyzed. Figure 14 shows both distributions at the $0^{\circ}$ (up) and $6^{\circ}$ (down) angles of flow attack. The distribution between tap positions is assumed to be linear in Figure 14. The mentioned non-symmetrical position in experiments causes a slightly non-symmetrical mean pressure coefficient distribution. Nevertheless, a more pronounced non-symmetrical distribution related to $C_{p}{ }^{\prime}$ distribution can be observed for $0^{\circ}$ angle of flow attack. Lower $C_{p}{ }^{\prime}$ values are observed at the down side of the section. The average relative error between the upper and down side is $14.63 \%$.

Main features of the flow mechanism around the fixed crosssection may be distinguished in Figure 14. The mean pressure distribution related to the $0^{\circ}$ angle shows a distinctive hump pattern at the upper and down sides of cross-section. The pressure distribution has large negative values and recovers excessive higher pressures downstream. This suggests that the flow separates at the leading edge and reattaches just upstream of the trailing edge [25]. The location of the reattachment point can be estimated based on the $C_{p}^{\prime}$ distribution. It is known that $C_{p}^{\prime}$ peak is strongly correlated with the time-averaged reattachment point [25].

Figure 14 also shows the rectangular cross-section where geometry is inclined at $\alpha=6^{\circ}$ with regard to the incoming flow. It is evident that the flow is fully separated on the upper surface of the rectangular cross-section based on the nearly uniform large negative pressure values. This angle of flow attack is already in the stall region as observed in Figure 12. Also, a separation bubble may be distinguished at the down side based on both mean and standard deviation distributions.
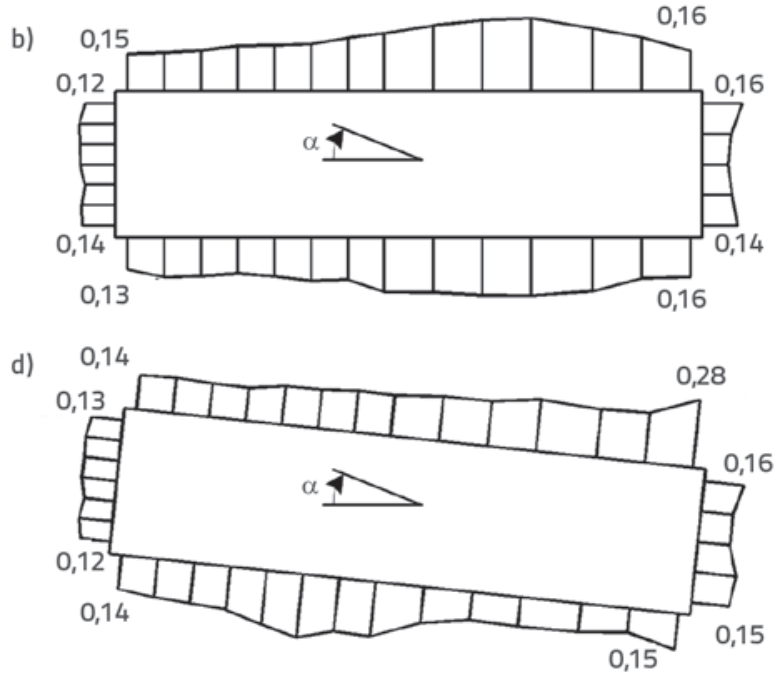

Figure 14. Mean (left-a) and c) and standard deviation (right-b) and d) pressure coefficient distributions for fixed rectangular case at $0^{\circ}$ (top-a) and b) and $6^{\circ}$ (bottom-c) and d) for $U=4.9 \mathrm{~m} / \mathrm{s}$. Provided values correspond to values at each corner 

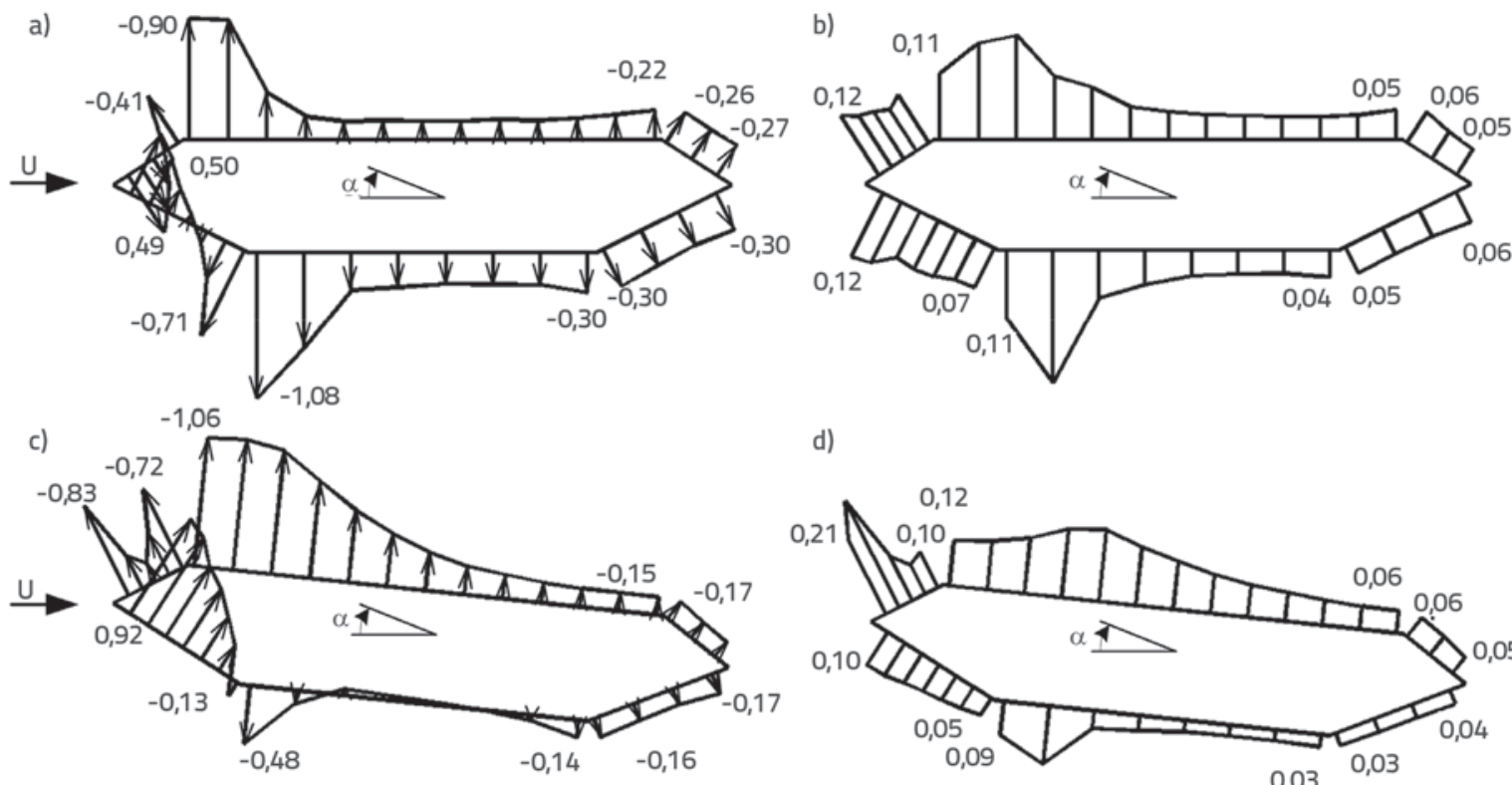

d)

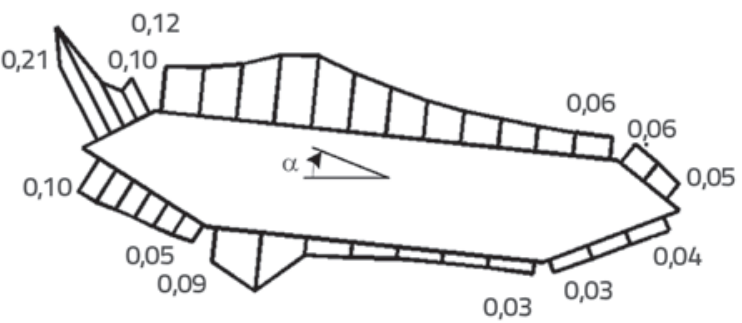

Figure 15. Mean (left-a) and c)) and standard deviation (right-b) and d)) pressure coefficient distributions for fixed bridge deck cases of $0^{\circ}$ (top -a) and b)) and $6^{\circ}$ (bottom -c) and d)) for $U=5.1 \mathrm{~m} / \mathrm{s}$. Provided values correspond to values at each corner.

The mean and standard deviation of pressure coefficients at the fixed bridge deck at $0^{\circ}$ (top) and $6^{\circ}$ (bottom) are depicted in Figure 15 . In both cases, separation bubbles are observed at the top and bottom corners of the windward side. For example, at $0^{\circ}$ angle of flow attack, the observed separation bubbles are smaller when compared to the rectangular cross-section. Results related to the $6^{\circ}$ degrees are not showing stall. Only larger separation at the top side and smaller at the bottom side is obtained, when compared to $0^{\circ}$.

All eight flutter derivatives of up to $U_{\text {red }}=30$, evaluated as described in Section 1.1.2, are presented for both cross-sections in Figure 16. Except for the case of $H_{3}$ derivative, where similarities between rectangular and bridge cross-section are observed, all other flutter derivatives exhibit different patterns. This is expected since the bridge cross-section is related to the more stream-lined section, while rectangular cross-section is representative of a bluff section. The most important difference observed in flutter derivatives presented in Figure 16 is related to the $A_{2}$ derivative, which is interpreted as aerodynamic torsional damping.

In particular, $A_{2}$ derivative helps in the classification of different types of flutter - classical vs torsional - as it is pointed out in [25]. In order to describe the effect of $A_{2}$ derivative, a simple model of the structure can be considered with only two degrees of freedom, vertical displacement $z$ and torsional degree $\alpha$ of freedom. Then equations of motion can be written as:

$m\left[\ddot{z}+2 \varsigma_{\mathrm{z}} \omega_{\mathrm{z}} \dot{z}+\omega_{\mathrm{z}}^{2}\right]=L_{\mathrm{ae}}$

$I\left[\ddot{\alpha}+2 \varsigma_{\alpha} \omega_{\alpha} \dot{\alpha}+\omega_{\alpha}^{2} \alpha\right]=M_{\mathrm{ae}}$

where $L_{\mathrm{ae}}$ and $M_{\mathrm{ae}}$ are aeroelastic forces given by Eq. (1) and Eq. (2), $m$ and $/$ are the mass and mass moment of inertia per unit length, $\zeta_{z}$ and $\zeta_{a}$ are damping ratios in heave and pitch and $\omega_{z}$ and $\omega_{\mathrm{a}}$ are corresponding still-air circular frequencies. Combining the torsional equation of motion (17) with the expression for aeroelastic moment (2), one obtains the coefficient of the term $\dot{\alpha}$, when corresponding contributions are reordered on the left hand side of the equation, as shown in the following expression:

$2 / \varsigma_{\alpha} \omega_{\alpha}-q B^{2} K A_{2}^{*} \frac{B}{U}$

Since the term involving $A_{2}$ can be understood as an aerodynamic contribution to the damping of the structure, the expression (18) can be treated as the effective or total damping. It follows that the effect of structural damping could be reduced or even eliminated by obtaining positive trend in the $A_{2}$ values, as it is obtained in the case of rectangular cross-section shown in Figure 16 , which results in an unstable situation. This destabilizing change of $A_{2}$ values results in torsional flutter (single degree of freedom flutter) and its critical velocity is obtained from the condition that the total damping is equal to zero.

It can therefore be concluded - based on the flutter derivative curves from Figure 16, in particular $A_{2}$ - that the symmetric bridge cross-section is prone to the two degree of freedom flutter while the rectangular one may enter into one degree of freedom flutter. Taking into account the criterion mentioned for rectangular section (Eq. 18), it can be expected that instability will happen slightly above $U_{\text {red }}=5$, i.e. when $A_{2}$ derivative changes the sign diminishing the structural damping. However, actual value of critical velocity depends of structural characteristics of the bridge. Related to the bridge deck section, a two degree of freedom flutter analysis including structural characteristics of potential structure is performed in [33], with higher reduced velocity than the critical one, even around $U_{\text {red }}=13$. A more 

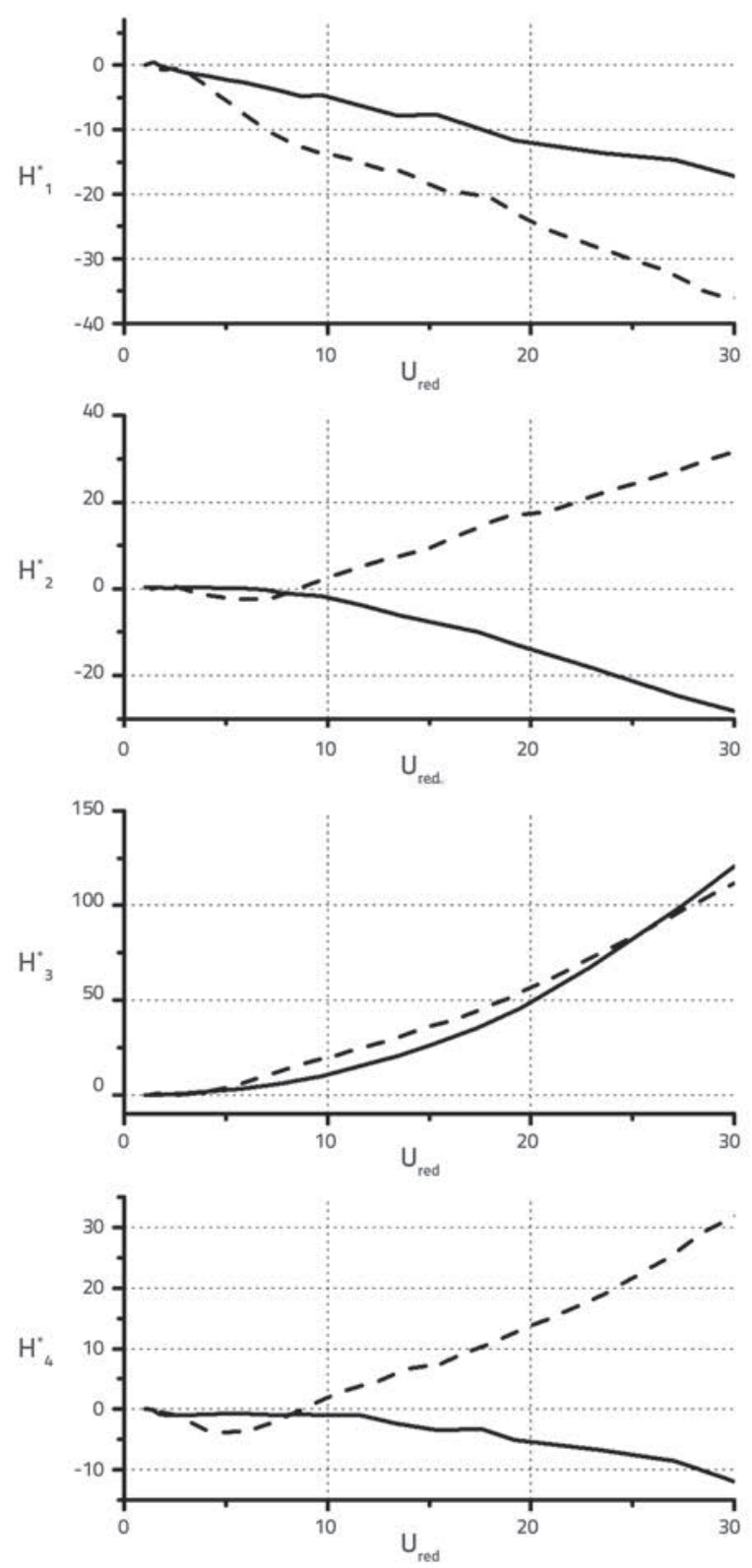
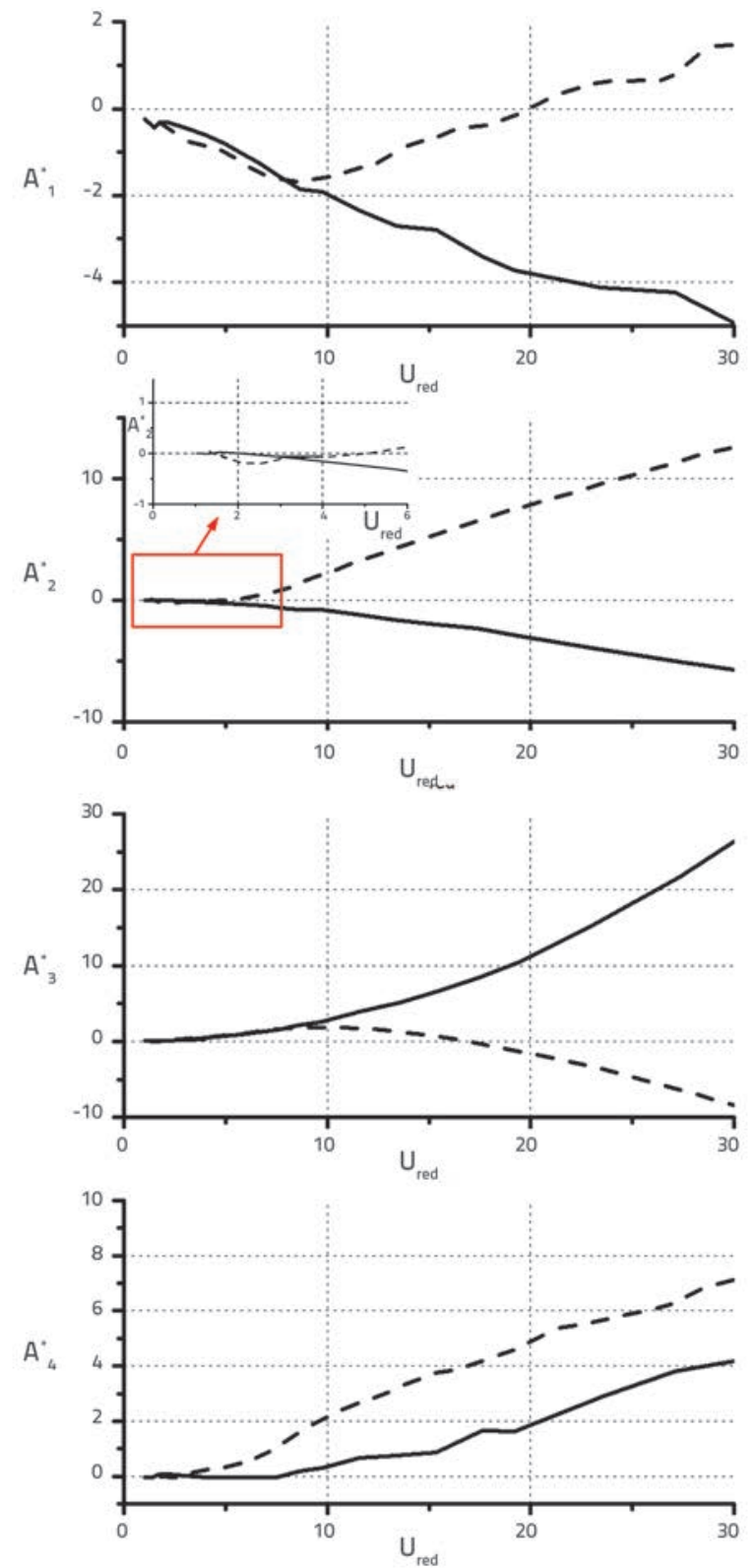

Figure 16. Measured flutter derivatives obtained for rectangular and bridge cross-section

detailed analysis should be conducted, including structural parameters, in order to make a clearer comparison between the proposed sections. Nevertheless, as stated in [8], generally trapezoidal box girders, prone to two degree of freedom flutter, appear to be the better choice for long span cable-supported bridges then sections prone to the one degree of freedom flutter, at least from the point of view of aerodynamic stability.

\section{Conclusions}

The main objective of this paper is to experimentally determine flutter derivatives related to two different cross-sections: a rectangular one and a typical bridge cross-section. Two types of measurements are performed: force balance measurements and pressure measurements. The paper presents summary of different experimental approaches related to the problem of aeroelasticity. Results are accompanied with a detailed description of the identification technique applied and an appropriate experimental set-up.

The description of evaluation procedure and results related to the Strouhal number, which is an important parameter that leads to vortex shedding phenomena, are presented. Stationary force coefficients are also evaluated, and the stall condition is observed in case of a bluffer rectangular cross-section. Main patterns for the flow around the tested cross-sections are recognized based on the mean and standard pressure distributions. In the end, eight flutter derivatives are estimated for both cross-sections. 
Besides the Strouhal number related to the typical bridge deck section, the evaluated flutter derivatives also constitute one of main contributions of this work. In particular, the evaluated flutter derivatives can be useful when aerodynamic stability of similar cross-sections is considered. Furthermore, the importance of the aeroelastic damping $A_{2}$ is emphasized. In particular, the bluff rectangular cross-section is distinguished as the cross-section that is prone to torsional flutter (one degree of freedom), whereas the bridge deck section is susceptible to traditional flutter.

\section{Acknowledgements}

The support of the German Academic Exchange Service (DAAD) to the author ASG in the framework of a long-term scholarship grant is gratefully acknowledged. The authors would like to thank Dr. Christian Neuhaus for the help related to the experiments as well as for fruitful discussions.

\section{Appendix}

In the case of vertical motion, the following loads act on the section model according to the given load model: the inertia and damping forces contrary to the motion and the aeroelastic force $\mathrm{L}_{\text {ae }}^{\mathrm{z}}$ in the direction of the motion [28], as shown in Figure 17.

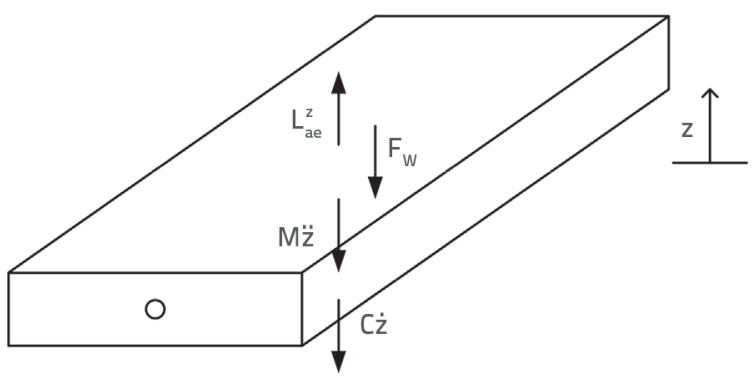

Figure 17. Forces acting on model placed in experimental set-up [28]

Building the equilibrium of vertical forces the load balance is cut off and the measured force $F_{w}$ acts as stress on the cut-free edge of the section model. This forms the following equation:

$M \ddot{z}+C \dot{z}+F_{\mathrm{w}}-L_{\mathrm{ae}}^{z}=0$

Using the presented approach for the aeroelastic forces given in Eq. (1) and the unit length of the section, the following equation can be derived:

$M \ddot{z}+C \dot{z}+F_{w}-\frac{1}{2} \rho U^{2} B\left[K H_{1}^{*} \frac{\dot{z}}{U}+K^{2} H_{4}^{*} \frac{z}{B}\right]=0$
Due to harmonic vertical motion with circular frequency $\omega$, the motion, and its first and second derivatives, can be expressed as:

$z=\hat{z} e^{i \omega t}, \dot{z}=\hat{z} i \omega e^{i \omega t}, \ddot{z}=-\hat{z} \omega^{2} e^{i \omega t}$

As already mentioned, two sets of measurements are performed, measurements in still air and under the action of wind, and due to the forced harmonic motion. The measured forces $F_{0}$ and $F_{\text {w }}$ are assumed to be harmonic as well and are presented in Eq. (5). Substitution of Eqs. (A3) and Eq. (5) in Eq. (A2) and cancelling $e^{i \omega t}$ in the resulting equation yields the following equation for the measured forces:

$\hat{F}_{\mathrm{w}} e^{i \varphi_{\mathrm{w}}}=\hat{z}\left[M \omega^{2}-i \omega C+\frac{1}{2} \rho U^{2} B\left(K H_{1}^{*} \frac{i \omega}{U}+K^{2} H_{4}^{*} \frac{1}{B}\right)\right]$

Here the measurement without wind $\left(F_{0}\right)$ is just a special case of the general approach with wind $\left(\mathrm{F}_{w}\right)$ :

$\hat{F}_{0} e^{i \varphi_{0}}=\hat{z}\left[M \omega^{2}-i \omega C\right]$

complex plane as shown in Figure 1, and their real and imaginary parts can be presented as follows:

$F_{\mathrm{w}}=\hat{F}_{\mathrm{w}} e^{i \varphi_{\mathrm{w}}}=\operatorname{Re}\left(F_{\mathrm{w}}\right)+i \cdot \operatorname{Im}\left(F_{\mathrm{w}}\right)=\hat{F}_{\mathrm{w}} \cdot \cos \left(\varphi_{\mathrm{w}}\right)+i \cdot \hat{F}_{\mathrm{w}} \cdot \sin \left(\varphi_{\mathrm{w}}\right)$

Using the Euler identity, the forces can be represented in the

$F_{0}=\hat{F}_{0} e^{i \varphi_{0}}=\operatorname{Re}\left(F_{0}\right)+i \cdot \operatorname{Im}\left(F_{0}\right)=\hat{F}_{0} \cdot \cos \left(\varphi_{0}\right)+i \cdot \hat{F}_{0} \cdot \sin \left(\varphi_{0}\right)$

The following is obtained by calculating the difference:

$\Delta F=F_{\mathrm{w}}-F_{0}=\operatorname{Re}\left(F_{\mathrm{w}}\right)-\operatorname{Re}\left(F_{0}\right)+i \cdot\left(\operatorname{Im}\left(F_{\mathrm{w}}\right)-\operatorname{Im}\left(F_{0}\right)\right)=\operatorname{Re}(\Delta F)+i \cdot \operatorname{Im}(\Delta F)$

Substituting Eq. (A4) and Eq. (A5) to Eq. (A8) in case of the lift aeroelastic force, we obtain:

$\Delta L_{\mathrm{ae}}^{\mathrm{z}}=\hat{z} \frac{1}{2} \rho U^{2} B\left(K H_{1}^{*} \frac{i \omega}{U}+K^{2} H_{4}^{*} \frac{1}{B}\right)$

Substituting reduced frequency, $K=B \omega / U$, in Eq. (A9), Eq. (7) is obtained:

$\Delta L_{\mathrm{ae}}^{\alpha}=\frac{1}{2} \rho U^{2} K^{2} \hat{z}\left(H_{4}^{*}+i H_{1}^{*}\right)$

Eq. (8-10) can be derived in a similar way.

\section{REFERENCES}

[1] Ricciardelli, F.: On the wind loading mechanism of longspan bridge deck box section, Journal of Wind Engineering and Industrial Aerodynamics, 91 (2003), pp. 1411-1430, https://doi. org/10.1016/j.jweia.2003.09.011

[2] Den Hartog, J. P.: Mechanical vibrations, Mc-Graw-Hill, 1956.

[3] Farquharson, F.B.: Aeroelastic stability of suspension bridges with special reference to the Tacoma Narrows Bridge, Part I-V, University of Washington Experimental Station. Bulletin 116, pp. 19491954. 
[4] Brownjohn, J.M.W., Jakobsen, J.B.: Strategies for aeroelastic parameter identification from bridge deck free vibration data, Journal of Wind Engineering and Industrial Aerodynamics, 89 (2001), pp. 1113-1136, https://doi.org/10.1016/S01676105(01)00091-5

[5] Scanlan, R. H., Tomko, J.: Airfoil and bridge flutter derivatives, Journal of the Engineering Mechanics Division Proceedings of the ASCE, 97 (1971), pp.1717-1737.

[6] Bisplinghoff, R.L., Ashley, H., Halfman, R.L.: Aeroelasticity, Dover science books, Dover, New York, 1996.

[7] Mannini, C.: Flutter Vulnerability Assessment of Flexible Bridge, PhD thesis, Technische Universitaet Carolo-Wilhelmina Braunschweig and University of Florence, 2006.

[8] Larsen, A., Larose, G.L.: Dynamic wind effects on suspension and cable-stayed bridges, Journal of Sound and Vibration, 334 (2015), pp. 2-28, https://doi.org/10.1016/j.jsv.2014.06.009

[9] Righi, M.: Aeroelastic stability of long span suspended bridges: Flutter mechanism on rectangular cylinders in smooth and turbulent flow, PhD thesis, University of Florence, 2003.

[10] Borri, C., Costa, C.: CISM courses and lectures, Springer Vienna, 2007.

[11] Dyrbye, C., Hansen, S.: Wind Loads on Structures, John Wiley \& Sons, first edition, 1997.

[12] Richardson, J.R.: The development of the concept of the twin suspension bridge, National Maritime Institute, NMI R125, 1981.

[13] Bartoli, G., D’Asdia, S., Mannini, C., Noè, S., Procino, L.: Innovative configurations for long-span suspension bridges, Proceedings of the European African Conference on Wind Engineering EACWE5, 2009.

[14] Johannson, J., Andersen, M.S., Øvre, M.S.: Non-flutter design principle for long span bridges, Proceedings of the Asia Pacific Conference on Wind Engineering APCWE8, 2013, https://doi. org/10.3850/978-981-07-8012-8_172

[15] Simiu, E., Scanlan, R. H.: Wind Effects on Structures: Fundamentals and Applications to Design, John Wiley, New York, $3^{\text {rd }}$ edition, 1996.

[16] Theodorsen, T.: General theory of aerodynamic instability and the mechanism of flutter, NACA technical report 496, 1934.

[17] Ge, Y., Xiang, H.: Computational models and methods for aerodynamic flutter of long-span bridges, Journal of Wind Engineering and Industrial Aerodynamics, 96 (2008), pp. 19121924, https://doi.org/10.1016/j.jweia.2008.02.017

[18] Noda, M., Utsunomiya, F., Nagao, F., Kanda, M., Shiraishi, N. Effects of oscilation amplitude on aerodynamic derivatives Journal of Wind Engineering and Industrial Aerodynamics, 91, 2003.
[19] Jensen, A.G., Höffer, R.: Flat plate flutter derivatives - an alternative formulation, Journal of Wind Engineering and Industrial Aerodynamics, 74-76 (1998), pp. 859-869, https://doi. org/10.1016/S0167-6105(98)00078-6

[20] Zasso, A.: Flutter derivatives: Advantages of a new representation convention, Journal of Wind Engineering and Industrial Aerodynamics, 60 (1996), pp. 35-47, https://doi.org/10.1016/01676105(96)00022-0

[21] Chowdhury, A.G., Sarkar, P.P.: A new technique for identification of eighteen flutter derivatives using a three-degree-of-freedom section model, Engineering Structures, 25 (2003), pp. 1763-1772, https://doi.org/10.1016/j.engstruct.2003.07.002

[22] Bogunović-Jakobsen, J.: Fluctuating wind load and response of a line-like engineering structure with emphasis on motion-induced wind forces, PhD thesis, University of Trondheim, Norway, 1995.

[23] Sarkar, P.P., Jones, N.P., Scanlan, R.H.: System identification for estimation of flutter derivatives, Journal of Wind Engineering and Industrial Aerodynamics, 41-44 (1992), pp. 1243-1254, https://doi. org/10.1016/0167-6105(92)90131-S

[24] Matsumoto, M.: Aerodynamic damping of prisms, Journal of Wind Engineering and Industrial Aerodynamics, 59 (1996), 159-175, https://doi.org/10.1016/0167-6105(96)00005-0

[25] Haan, F.: The effects of the turbulence on the aerodynamics of long-span bridges, PhD thesis, Department of Aerospace and Mechanical Engineering, University of Notre Dame, Indiana, 2000.

[26] Neuhaus, C.: Zur Identifikation selbsterregter aeroelastischer Kräfte im Zeitbereich, PhD thesis, Bergischen Universitaet Wuppertal, Wuppertal, 2010

[27] Hortmanns, M.: Zur Identifikation und Berücksichtigung nichtlinearer aeroelasticher Effekte, PhD thesis, RWTH Aachen, 1997.

[28] Neuhaus, C., Roesler, S., Höffer, R., Hortmanns, M., Zahlten, W.: Identification of 18 flutter derivatives by forced vibration tests a new experimental rig, In European and African Conference on Wind Engineering, 2009.

[29] Neuhaus, C.: Numerische frequenzabhängige Kalibrierung langer Druckmessschlauchsysteme, Technical report, Ruhr University Bochum, Bochum, Germany, 2010.

[30] Strouhal, V.: Über eine besondere Art der Tonerregung, Annalen der Physik und Chemie, pp. 216-251, 1878.

[31] Eurocode 1: Actions on Structures, Part 1-4: General actions-Wind actions (EN 1991-1-4: 2005).

[32] Brčić, S.: Uticaj vetra na konsrukcije. In V. Brčić, editor, Savremeni problem dinamike inženjerskih konstrukcija, JGC, GRF, Beograd, pp. 581-693, 1982

[33] Šarkić, A., Jočković, M., Brčić, S.: Frequency- and Time-Domain Methods Related to Flutter Instability Problem, Građevinski materijali i konstrukcije, 57 (2014) 2, pp. 39-56. 